\title{
RECORD OF DARKLING BEETLES (COLEOPTERA: TENEBRIONIDAE) FROM MIZORAM STATE, INDIA
}

\author{
Vishwanath Dattatray Hegde* and Sarita Yadav
}

North Eastern Regional Centre, Zoological Survey of India, Risa Colony, Shillong, Meghalaya-793003

*Corresponding author. Email: hegde67@yahoo.co.in

\section{Article history \\ Received: 14 May 2020; \\ accepted 19 October 2020}

\section{Keywords:}

Mizoram; Tenebrionidae; new record; Northeast India
Abstract. The earlier compiled collections of Tenebrionidae held at the North Eastern Regional Centre, Zoological Survey of India, Shillong were identified. The present study reports five species of Tenebrionidae belonging to three genera under three tribes of two subfamilies. The collected and identified Tenebrionid species are reported from the Mizoram state for the first time. The synonyms, distribution and images are also provided.

\section{INTRODUCTION}

The representatives of the Coleopteran family Tenebrionidae are commonly known as darkling beetles. Tenebrionidae are one of the most diverse beetle families. They are usually dark, multi-colored and/or patterned, sometimes with reddish elytra. Their body is variable in shape, varying from elongated to more oval, usually flattened. Many large species are flightless and have fused elytra. Characteristics of Tenebrionidae: first abdominal sternite entire, not divided by hind coxae (unlike Carabidae), eyes usually notched, antennae variable [thread-like (filiform), bead-like (moniliform), or clubbed], typically 11-segmented, with insertion concealed from above, tarsal formula is 5-5-4. Larvae are cylindrical and hard-bodied and are called "false wireworms" because they resemble click beetle larvae (Matthews and Bouchard 2008).

The North East Indian (NEI) Region with its rich evergreen and subtropical vegetation is an important zone of the rich beetle fauna of India. However, the exploration and inventory of the beetle fauna in this region is still far from adequate. (Dasgupta and Hegde 2012). Mizoram is one of the eight states in the North Eastern Region of India. It is situated between $21^{\circ} 58^{\prime}$ to $24^{\circ} 35^{\prime} \mathrm{N}$ latitude and $92^{\circ} 15^{\prime}$ to $93^{\circ} 29^{\prime} \mathrm{E}$ longitude and covers an area of nearly $21,087 \mathrm{sq}$. $\mathrm{km}$. It shares borders with three states of the Seven Sister States, namely Tripura, Assam and Manipur, and two neighbouring countries, i.e. Bangladesh and Myanmar. The geographic location of the state is unique as it is divided into two parts by the Tropic of Cancer. The Mizoram State contains numerous streams and rivers and small patches of flat area, the largest of which falls into the Champhai District. As to the beetle Fauna of Mizoram (Zoological Survey of India State Fauna Series No. 14, 2007), several families of coleoptera have been studied by different scientists, but the study of Tenebrionidae is still lacking.

The recently performed taxonomic study of the beetles collected from Mizoram has resulted in the identification of five different species of darkling beetles, viz. Cerogria basalis, Luprops rugosissimus, Gonocephalum bilineatum, G. simulatrix and G. tuberculatum, first reported for the fauna of the Mizoram state (Figure 1). The present paper gives a taxonomic account of the material.
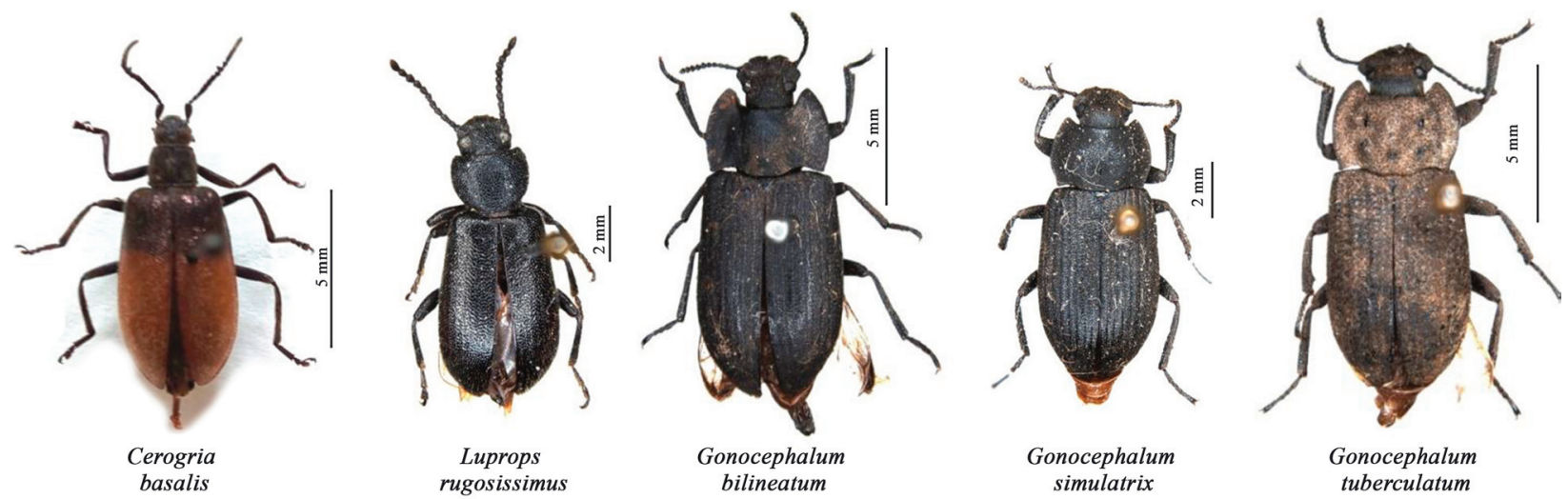

Figure 1. Five different species of darkling beetles. 


\section{MATERIALS AND METHODS}

The specimens of Tenebrionidae collected by different research workers since 1979 and deposited at the North Eastern Regional Centre, Zoological Survey of India, Shillong were sorted out, set-pinned and identified by their morphological characters and, sometimes, by their dissected male genitalia. The identification of Cerogria species was confirmed by Yong and Bin (2014) and that of Luprops by Sabu et al. (2007). After identification, these species were classified as per the method described by Bouchard et al. (2005). The synonyms and distribution of Gonocephalum species were taken from Iwan et al. (2010). The photos were taken with the help of Leica M 205A stereo-zoom microscope. All the identified specimens were registered and deposited in the National Zoological Collection of the North Eastern Regional Centre, Zoological Survey of India, Shillong. Registration numbers are given for each species.

\section{SYSTEMATIC ACCOUNT}

\section{Family: Tenebrionidae}

Subfamily: Lagriinae Latreille, 1825 (1820)

Tribe: Lagriini Latreille, 1825 (1820)

\section{Cerogria basalis (Hope, 1831)}

1831. Lagria basalis (Hope): The Zoological Miscellany: 1831: 32.

1836. Lagria basalis Dohrn: Entomologische Zeitung (Stettin), 47: 353.

1915. Cerogria basalis Borchmann Archiv fur Naturgeschichte, 81: 113.

1936. Cerogria basalis Borchmann, Louis DesmetVerteneuil, Brussels: 135.

Material examined: 03 ex. Farpak, Mizoram, 10.v. 1993, S.J. S. Hattar coll. Reg. No. I/COL/NERC-91.

Distribution: INDIA: Sikkim, West Bengal (Kalimpong \& Darjeeling) and Mizoram (New record).

Elsewhere: Nepal.

\section{Tribe: Lupropini Ardoin, 1958}

\section{Luprops rugosissimus Kaszab, 1980}

Luprops rugosissimus Kaszab, 1980, Acta zool. Acad. Sci. Hungaricae, XXVI (I): 195.

Material examined: 03 ex. Champhai dist., Mizoram, 16.iii.1979, P.T. Cherian coll. Reg. No. I/COL/NERC101.

Distribution: INDIA: Uttar Pradesh, Manipur, Mizoram (New record), Chhattisgarh, Pondicherry and Kerala. Elsewhere: Sri Lanka.

\section{Subfamily: Tenebrioninae Latreille, 1802}

Tribe: Opatrini Brulle, 1832

\section{Gonocephalum bilineatum (Walker, 1858)}

1858. Opatrum bilineatum Walker, Annals and Magazine of Natural History (3) 2: 284.

Hopatrum bilineatum Walker, 1858. - Gemminger 1870: 1931.

Gonocephalum bilineatum (Walker, 1858). - Gebien 1910b: 322,1921: 269, 1939: 446; Chatanay 1917: 238; Blair 1921: 269; Schuster1928: 989; Reichardt 1936: 109; Kaszab 1952a: 641, 1954: 75, 1965a:114, 1965d: 287, 1970a: 424, 1977: 257, 1979a: 260, 1979b: 65, 1980b:171; Boddy 1965: 171; Kwon and Choi 1986: 106; Schawaller 1997a:3; Hua Li 2002: 138; Iwan and Löbl 2008: 263.

Gonocephalum kamtschaticum Motschulsky, 1860: 139.

Hopatrum kamtschaticum Motschulsky, 1860. - Gemminger 1870:1932.

Gonocephalum kamtschaticum Motschulsky, 1860. Reitter 1904:146; Gebien 1910b: 323; Schuster 1928: 989; Reichardt 1936: 109; Kaszab 1952a: 682, 1965d: 287.

Blapstinus latifrons LeConte, 1874: 70. - Casey 1890: 393.

Gonocephalum latifrons (LeConte, 1874). - Champion 1895: 115; Gebien 1910b: 323, 1939: 452; Kaszab 1952a: 682; Ferrer 2000: 129.

Opatrum orarium Lewis, 1894: 380. - Champion 1895: 117.

Gonocephalum orarium (Lewis, 1894). - Gebien 1910b: 324; Reichardt 1936: 109; Schuster 1928: 989; Kaszab 1952a: 682.

Material examined: 06 ex. Zote, Champhai, Mizoram, 16.iii.1979, P.T. Cherian coll. Reg. No. I/COL/ NERC-126.

Distribution: India: Uttarakhand, Sikkim, Uttar Pradesh, West Bengal, Mizoram (New record), Chhattisgarh and Andaman Is.

Elsewhere: Canada, Russia, Japan, Korea, China, Bhutan, Nepal, Hawaii, the Philippines, Vietnam, Sri Lanka, Malaysia, Indonesia, Caroline Is., Fiji and New Caledonia.

\section{Gonocephalum simulatrix (Fairmaire, 1891)}

1891. Pseudoblaps simulatrix Fairmaire, Annales de la Societe Entomologique de Belgique: C.

Gonocephalum simulatrix (Fairmaire, 1891). - Gebien 1935: 317,1939: 446; Reichardt 1936: 107; Schuster 1936: 193; Gridelli 1954: 283; Kaszab 1952: 653, 1960 : 151, 1961: 4; 1961: 351, 1965 :669, 1968: 20, 1970: 
153, 1974a: 193, 1977: 259; Schawaller 1997:12; Iwan and Löbl 2008: 266.

Scleropatrum infimum Fairmaire, 1896: 57.

Gonocephalum infimum (Fairmaire, 1896). - Gebien 1939: 446; Kaszab 1952a: 683.

Gonocephalum martensi Kaszab, 1977 n. syn.

Material examined: 17 ex. $2 \mathrm{~km}$ from Murlen village, Champhai, Mizoram, 07.xi.2018, Uttam Saikia coll. Reg. No. I/COL/NERC-128.

Distribution: India: Jammu and Kashmir, Himachal Pradesh, Uttarakhand, Uttar Pradesh and Mizoram (New record).

Elsewhere: China, Afghanistan, Pakistan and Nepal.

\section{Gonocephalum tuberculatum (Hope, 1831)}

1831. Opatrum tuberculatum Hope, The Zoological Miscellany: 31.

Gonocephalum tuberculatum (Hope, 1831). - Chatanay, 1917: 243; Miwa, 1931: 151; Gridelli 1934: 67; Reichardt 1936: 108; Gebien 1939: 446; Kaszab 1941: 51, 1952: 464, 1960: 139, 1961: 236,1968: 19, 1970: 423, 1970: 145, 1973b: 55, 1974: 193, 1980: 171; Gridelli 1954: 283; Nakane 1966: 243; Schawaller 1997: 13; Hua Li 2002: 139; Iwan and Löbl 2008: 266.

Hopatrum elongatum Guérin-Méneville, 1834. - Fairmaire 1894: 17; Gemminger, 1870: 1931.

Opatrum elongatum Guérin-Méneville, 1834: 32.

Gonocephalum elongatum (Guérin-Méneville, 1834) Gebien 1910b:323, 1913: 4; Schuster 1928: 989; Reichardt 1936: 108; Kaszab 1952a: 672.

Gonocephalum quadrinodosum Reitter, 1904: 146. Gebien 1910b: 325, 1939: 446; Schuster 1928: 989 (= Opatrum elongatum Guérin-Méneville, 1834); Reichardt 1936: 108 (= Opatrum elongatum Guérin-Mén. eville, 1834); Kaszab 1952: 672.

Material examined: 04 ex. Zote, Champhai, Mizoram, 16.iii.1979, P.T. Cherian coll. Reg. No. I/COL/ NERC-127.

Distribution: INDIA: Kashmir; Himachal Pradesh, Uttarakhand, Sikkim, West Bengal, Uttar Pradesh, Mizoram (New record) and Chhattisgarh.

Elsewhere: China, Afghanistan, Pakistan, Nepal, Taiwan, Bangladesh, Myanmar, the Phillippines and Vietnam.

\section{DISCUSSION}

The present paper is based on the identification of the material present in the National Zoological Collection of the Zoological Survey of India, Shillong. It contains the report on five species under three genera and three tribes of two sub-families of the family Tenebrionidae collected from Mizoram. Three out of the five abovementioned species are attributed to the genus Gonocephalum. The genus Gonocephalum is recorded almost everywhere including the Himalayan region, which is possibly due to the remarkable range of its adaptation abilities such as heavy sclerotization, long lifespan, dark colour, mostly crepuscular lifestyle, ability to live in the soil, under the stones, litter, logs or tree trunks and guano of birds and mammals (Schawaller 1997; Hegde et al. 2018). It has been first documented in Mizoram, one of the states of the North Eastern Region. The Eastern Himalayas region hosts a large number of Tenebrionid species (106 species from Sikkim and 63 species from Arunachal Pradesh), the diversity of the same species being markedly lower in the Indo-Burma region (13 species from Manipur and 37 species from Meghalaya) (Hegde 2019a, b; Hegde and Lal 2016). This study has deepened the knowledge of Tenebrionidae. In addition, results of our study infer that investigations of the Tenebrionid fauna in the area are promising and, therefore, should be continued.

\section{ACKNOWLEDGEMENTS}

We are very much thankful to Dr. Kailash Chandra, Director, Zoological Survey of India, Kolkata for the facilities provided. Our thanks also go to the staff of North Eastern Regional Centre, Shillong for their constant encouragement.

\section{REFERENCES}

Bouchard, P., J. F. Lawrence, A. E. Davies, and A. F. Newton. 2005. Synoptic classification of the world Tenebrionidae (Insecta: Coleoptera) with a review of familygroup names. Annales Zoologici 55: 499-530.

Dasgupta, J., and V. D. Hegde. 2012. Record of pleasing fungus beetles (Coleoptera: Erotylidae) from Tripura state, India. Records of the Zoological Survey of India 112 (3): 313-315.

Fauna of Mizoram. 2007. State Fauna Series 14: 1-691, published by Director Zoological Survey of India, Kolkata.

Hegde, V. D. 2019a. Checklist of Darkling Beetles (Coleoptera: Tenebrionidae) of Arunachal Pradesh, India. Zoological Survey of India 119 (1): 69-77.

Hegde V. D. 2019b. To the knowledge of Darkling Beetles (Coleoptera: Tenebrionidae) from the Indo-Burma Biodiversity Hotspot, Meghalaya, India. Journal of Threatened Taxa 11 (15):15074-15078.

Hegde, V. D., and B. Lal. 2016. Darkling Beetles (Ten- 
ebrionidae: Coleoptera) of Manipur with one new record from India. Biological Forum - An International Journal 8 (2): 01-04.

Hegde, V. D., S.V. Manthen, and B. Kulkarni. 2018. The Genus Gonocephalum Solier, 1834 (Coleoptera: Tenebrionidae: Tenebrioninae) from Maharashtra with some new records. Indian Forester 144 (5): 465-470.

Iwan, D., J. Ferrer, and M. Ras. 2010. Catalogue of the world Gonocephalum Solier, 1834 (Coleoptera: Tenebrionini: Opatrini) Part 1. List of the species and subspecies. Annales Zoologici (Warszawa) 60 (2): 245-304.

Matthews, E. G., and P. Bouchard. 2008. Tenebrionid beetles of Australia: descriptions of tribes, keys to genera, catalogue of species. Canberra: Australian Biological Resources Study viii: 398.

Sabu, T. K., O. Merk1, and P. Abhita. 2007. A new Luprops species from Western Ghats with redescription and identification key to the species of Indian Peninsula and Sri Lanka (Tenebrionidae: Lagriinae: Lupropini). Zootaxa1636: 47-58.

Schawaller, W. 1997. The genus Gonocephalum Chevrolat (Coleoptera: Tenebrionidae) in the Nepal Himalayas. StuttgarterBeitrung of Naturkunde (A) 559: 1-18.

Yong, Z., and C. Bin. 2014. Redescription of Cerogria basalis (Hope, 1831) (Coleoptera: Tenebrionidae: Lagriinae). Entomotaxonomia 36 (4): 252-256. 